\title{
Wind Wave Effects on Hydrodynamic Modeling of Ocean Circulation in the South China Sea
}

\author{
Hong Zhang ${ }^{1, *}$, S. A. Sannasiraj ${ }^{2}$ and Eng Soon Chan $^{3}$ \\ ${ }^{1}$ Griffith School of Engineering, Griffith University, Gold Coast Campus, QLD 4215, Australia \\ ${ }^{2}$ Department of Ocean Engineering, Indian Institute of Technology Madras, Chennai, 600036, India \\ ${ }^{3}$ Department of Civil Engineering, National University of Singapore, Singapore 119223
}

\begin{abstract}
Wind, wave and current interactions control the boundary fluxes, momentum and energy exchange between the atmosphere and the ocean, and within the water column. The wind wave effect on the circulation is investigated in a threedimensional time-dependant ocean circulation model. This POM (Princeton Ocean Model) based model is implemented with realistic coastlines in South China Sea and emphasizes the simulation of physical parameters in the water column. Taking account of the wind waves, an increase in air-sea drag coefficient, reflecting an enhanced sea surface roughness due to increased wave heights, is shown to improve the simulated surface current and the sea surface elevation. It is also found that developing waves with smaller peak periods influenced the surface circulation more significantly. The inclusion of the wind wave parameterization also affects the current near the seabed in the shallow water.

The model is validated against current, temperature and salinity data measured in the Asian Seas International Acoustics Experiment (ASIAEX). The simulation results in the period of April - May 2001 show that wave-induced surface stress increases the magnitude of currents both at the surface and near the seabed. On the other hand, wave-induced bottom stress retards the near bottom currents in shallow water. Therefore the net effect of wind waves on circulation depends on the significance of current and elevation changes due to wind waves through both the surface and the bottom.
\end{abstract}

Key Words: Wave-current interaction, Bottom roughness, Surface stress, Ocean circulation model, Model coupling.

\section{INTRODUCTION}

In the ocean environment, the physical processes governing the water column are influenced by atmospheric flow, currents, surface waves, tides and their mutual interactions. A better understanding of the physical process is essential for studying the chemical and biological processes in scientific and practical applications, such as beach erosion, upwelling, storm surges and transport of various materials. Compared to high cost of field measurements, the numerical model for solving time dependent flows is both effective and economical. Extensive and intensive studies of ocean modeling have been undertaken in last a couple of decades. Ocean models have become an important tool for understanding the seasonal ocean circulation and thermal structure, and for establishing a nowcast system for regional seas.

The South China Sea (SCS) has complex bottom topography and open boundaries. The hydrodynamics in the region is very complicated. Metzger and Hurlburt [1] first applied a layered model to the SCS and compared upper layer currents and sea levels of the model with the observed data. Recently, Cai et al. [2] developed a coupled single-layer/ two-layer model to study the upper circulation. An enhanced

*Address correspondence to this author at the Griffith School of Engineering, Griffith University, Gold Coast Campus, QLD 4215, Australia;

E-mail: hong.zhang@griffith.edu.au understanding of the circulation characteristics has been achieved. Chu and Chang [3, 4] studied the seasonal thermodynamics in the SCS using the POM with limited boundary conditions, monthly mean climatological wind stress data set $[5,6]$ and bi-monthly variation of mass transport at the open boundaries $[7,8]$.

Wind wave impact on the ocean circulation is an important aspect of the hydrodynamics. Recent computational studies by Davies and Xing [9], Xie etc al. [10] and Moon [11] bear this point. Their studies show that the wave contributes to local current and sea level changes, and momentum and stratification mixing throughout the whole water column. Moon [11] also investigated the effects of ocean waves on sea surface temperature simulations. Without considering the wave effect at the surface, the surface stress is a function of wind speed based on the drag coefficient [12]. However, the action of wind over the sea induces the exchange of momentum between air and ocean, leading to wave development. Therefore the surface stress would be significantly enhanced by the wind waves. Charnock [13], Janssen [14, 15] and Donelan et al. [16, 17] presented various models to calculate surface roughness by taking into account the effects of the surface waves. Most recently, Massel and Brinkman [18] presented an analytical solution for the wave-induced set-up and flow through simple shoal geometry when water depth is a linear function of distance. The existing empirical knowledge has shown that surface 
waves enhance the mixing in the upper ocean, which can be applied to the newly derived continuity, momentum and energy equations for more accurate modeling. Mellor [19] and Qiao et al. [20] coupled surface wave equations to mixing equations in three-dimensional ocean models. Their result has confirmed a strong wave-induced mixing in both hydrodynamics and temperature. Graig and Banner [21] and Zhang and Chan [22] have suggested that surface waves can enhance mixing in the upper ocean. The SCS is monsoon dominated, and surface waves play a significant role in the circulation process.

Wind waves cause an enhancement of the bottom stress encountered by currents, which has been studied theoretically (e.g. [23]) and experimentally (e.g. [24]; [25]). The orbital motions of the waves alternate near bottom currents, resulting in a thin boundary layer with intensive turbulence [26]. In ocean modelling, bottom friction is always considered to be quadratic of current velocities. It was demonstrated that the bottom friction can be greatly increased by the periodic bottom stress created by ocean waves by Grant and Madsen [27, 28], and this result has been tested and applied in a variety of coastal situations [29, 30]. Recently, Zhang and Li [31], Xie et al. [10] and Zhang et al. [32] incorporated the wave-current interaction mechanism proposed by Grant and Madsen [28] in a hydrodynamic model. Their results indicate that the surface waves can significantly affect the bottom currents by modifying the bottom drag coefficient. However, experimental results [25] show that the apparent hydraulic roughness proposed by Grant and Madsen [28] was under predicted. A modified model was proposed in Madsen [33], which showed excellent agreement with measurement data. The SCS has a complex bathymetry with water depth from a few meters up to 5000 meters. Previous studies have shown that the bottom effect of surface waves is significant in shallow regions [11,32]. Therefore, it is necessary to couple the wave module into circulation modeling in the SCS.

In the present study, the wind wave effect to the circulation is investigated using a three-dimensional timedependant Princeton Ocean Model (POM) based model. The model is configured with realistic coastlines in the South East Asian Seas and our emphasis is on the simulation of physical parameters in the water column. A third-generation wave model (WAM) is employed to predict the wave parameters. The wind wave effect on the circulation is examined by applying the theory of Janssen [21] to estimate the effect of waves on the sea surface roughness. At the bottom boundary layer, the wave-current interaction mechanisms as developed by the latest Grant-Madsen analytical model [33] are applied, which produce values of the bottom roughness experienced by a current, the apparent bottom roughness, from knowledge of wind-waves and bottom current shear stress characteristics. The improved formulations of surface stress and bottom stress have been incorporated into the POM model. The simulation results in the period of April May 2001 show that the surface stress with the consideration of waves increases, and as a consequence the magnitude of currents both at the surface and near the seabed has been varied. It is also found that young waves with smaller peak periods influenced the surface circulation more significantly than in old waves. On the other hand, wave-induced bottom stress retards the currents in the water column. Therefore the net effect of wind wave on the circulation depends on the significance of current and elevation changes due to surface stress and bottom stress respectively. The model is validated against the current, temperature and salinity data measured in the ASIAEX field measurements.

\section{MODEL DESCRIPTION}

\subsection{Circulation Model}

The flow equations governing ocean circulation in POM consists of the hydrostatic, the Boussinesq Navier-Stokes equations along with an equation of state which incorporates the temperature and salinity of the fluid velocity. The hydrostatic assumption and the Boussinesq approximation are commonly used in ocean circulation modeling based on the premise that the horizontal extent is much larger than the vertical extent. The governing equations of the continuity equation, the Reynolds momentum equations, the conservation equations for potential temperature and salinity and the turbulent kinetic energy are thus formulated in orthogonal Cartesian co-ordinates with $x$ increasing in the eastward direction, $y$ increasing in the northward direction and $z$ measuring vertically upwards from an undisturbed water level [19].

\subsection{Wave Model}

In the present study, a third-generation wave model, WAM [34] was adopted. WAM estimates the evolution of the energy spectrum for ocean waves by solving the wave transport equation explicitly without any presumptions on the shape of the wave spectrum.

The net source functions of the whole system takes into account all physical processes which contribute to the evolution of the wave spectrum, representing source terms due to wind input, non-linear wave-wave interaction and dissipation due to wave breaking and bottom friction.

The synthesis of these source terms as expressed in WAM [34] signifies the current state of understanding of the physical processes of wind waves, namely that inputs from these processes balance each other to form self similar spectral shapes corresponding to the measured wind wave spectra. Except for the non-linear source term, all the other source terms are individually parameterized to be proportional to the action density spectrum. The non-linear source uses the discrete interaction approximation (DIA) to simulate a non-linear transfer process, representing the four-wave resonant interaction Boltzmann equation and this characterizes the third-generation models.

\subsection{Models' Coupling}

\subsubsection{Coupling Through the Surface}

Winds blowing at the sea surface constitute an important driving force for ocean currents. Generally, the wind stress at the surface is therefore a necessary forcing parameter for an 
ocean circulation model. The surface wind stress over the ocean is directly correlated to the wind vectors. Normally, the wave-independent zonal $\left(\tau_{s x}\right)$ and meridional $\left(\tau_{s y}\right)$ components of the wave-independent stress are defined as

$$
\begin{aligned}
& \tau_{s x}=\rho_{a} C_{D} V_{10} u_{10}, \\
& \tau_{s y}=\rho_{a} C_{D} V_{10} v_{10}
\end{aligned}
$$

where $\rho_{a}$ is the air density; $\left(u_{10}, v_{10}\right)$ are the $(x, y)$ components of wind speed $V_{10}$ at $10 \mathrm{~m}$ above water; $C_{D}$ is the surface drag coefficient. Initially, the drag coefficient formulation is based on Large and Pond [12] modified for low wind speeds as suggested by Trenberth [35]:

$$
C_{D}= \begin{cases}2.18 \times 10^{-3} & \text { for } V_{10} \leq 1 \mathrm{~m} / \mathrm{s} \\ \left(0.62+\frac{1.56}{V_{10}}\right) \times 10^{-3} & \text { for } 1 \mathrm{~m} / \mathrm{s}<V_{10}<3 \mathrm{~m} / \mathrm{s} \\ 1.14 \times 10^{-3} & \text { for } 3 \mathrm{~m} / \mathrm{s} \leq V_{10}<10 \mathrm{~m} / \mathrm{s} \\ \left(0.49+0.065 V_{10}\right) \times 10^{-3} & \text { for } V_{10} \geq 10 \mathrm{~m} / \mathrm{s}\end{cases}
$$

The above equation has been commonly applied in ocean modeling, however it doesn't include the wave effect. As the wind blows over the ocean, surface waves are developed. The young waves significantly enhance the surface roughness and hence, surface stress due to waves should be considered $[17,34,36,37]$

The surface stress of airflow over sea waves depends on the sea state. From a consideration of the momentum balance of air it is found:

$$
\tau=\rho_{a} C_{D} V_{10}^{2},
$$

where the drag coefficient can be expressed by the shear velocity definition as:

$C_{D}=\left\{\kappa /\left(\ln \left(z / z_{0 s}\right)\right)\right\}^{2}$.

Here $\kappa=0.4$ and the surface roughness

$$
z_{0 s}=\frac{\alpha \tau}{g} / \sqrt{\left(1-\left(\tau_{w}\right) / \tau\right)}
$$

where $\alpha$ is the Charnock constant [5], $\tau$ is the total surface stress and $\tau_{W}$ is the wave-induced stress equals the amount of the momentum going to the waves due to wind.

Because only the developing waves contribute to the surface roughness, the direction of those waves follows the direction of wind closely. Equation (2) applies the direct paramerisation of $C_{D}$ on wind speeds, however the improved formulation of equation (4) which is indirect paramerisation through a surface roughness height is coupled into the model. Drag coefficient in equation (4) is a more physically sound parameter. The sur face roughness may vary for the same wind speed, and also associate with water depth, wave age or wind direction. The total shear stress due to wind and wave has been taken into account. Bye et al. [38] also proposed a formulation to calculate the shear stress with more complicated consideration of the momentum transfer from the ocean to the atmosphere through the swell.

\subsubsection{Coupling Through the Bottom}

The enhanced near bottom turbulence due to the presence of wind waves influences the flow field. The theory of wavecurrent interaction mechanisms of the Grant-Madsen analytical model [33] is applied.

If $z=z_{r}$ is close enough to the bottom to be considered within the constant stress layer, the concept of a bottom friction factor can be defined by

$\tau_{\mathbf{b}}=\rho C_{z_{r}}\left|\mathbf{U}_{\mathbf{r}}\right| \mathbf{U}_{\mathbf{r}}$,

where $\mathbf{U}_{\mathbf{r}}$ is the reference velocity used in "drag-law formulation", i.e. $\left|\mathbf{U}_{\mathbf{r}}\right|=U\left(z_{r}\right), \rho$ is the density of water and $C_{z_{r}}$ is bottom friction coefficient referenced to $U$ at $z=z_{r}$. The bottom friction coefficient can be expressed using the shear velocity definition as follows,

$C_{z_{r}}=\left[\kappa / \ln \frac{z_{r}}{Z_{0 b}}\right]^{2}$,

where $\kappa=0.4$ and $Z_{0 b}$ is often related to the bottom roughness, $k_{N}$. For example, $k_{N}=30 Z_{o b}$, for fully rough turbulent flow.

Based on skin friction, the Shields Parameter, $\psi_{m}^{\prime}$ can be calculated following the model presented by Madsen [33],

$\Psi_{m}^{\prime}=\frac{U_{*_{w m}}^{\prime}{ }^{2}}{(s-1) g d}$,

with

$U_{* w m}^{\prime}{ }^{2}=\frac{1}{2} f_{w}^{\prime} U_{b m}^{2} \quad$ and

$f_{w}^{\prime}=\exp \left\{5.61\left(\frac{U_{b m}}{d \omega_{r}}\right)^{-0.109}-7.30\right\}$,

where $d$ is sediment diameter and $s$ is the ratio of density of sediment to density of water; $U_{b m}$ is the amplitude of the equivalent periodic wave of near-bottom orbital velocity; and $U_{*_{w m}}$ is the maximum friction velocity due to windwaves. The movable bed roughness can then be evaluated by the following conditions [33]:

$$
\begin{aligned}
& k_{N}=d \quad \text { for } \quad \Psi_{m}^{\prime}<\frac{\Psi_{c r}}{2} \\
& k_{N}=4 \frac{U_{b m}}{\omega_{r}} \times\left\{\begin{array}{lll}
1.8 \times 10^{-2} Z^{-0.5} & \text { for } & Z<0.012 \\
7.0 \times 10^{-4} Z^{-1.23} & \text { for } & 0.012<Z<0.18
\end{array}\right. \\
& k_{N}=15 \Psi_{m}^{\prime} d \quad \text { for } Z>0.18 \text { or } \Psi_{m}^{\prime}>0.35
\end{aligned}
$$

where $\Psi_{c r}$, the critical value of Shields Parameter for the initiation of sediment motion, is obtained as a function of the fluid-sediment parameter $S_{*}=\frac{d}{4 v} \sqrt{(s-1) g d}$ from the modified Shields Diagram [28] and its extension [33]; and $Z=\Psi_{m}^{\prime} / S_{*} ; v$ is the fluid viscosity. 
The near-bottom wave velocity and bottom shear stress may be evaluated in terms of the directional surface wave components. A wind-wave model typically would have output in the form of the directional wave spectrum $S_{\eta \eta}(\omega, \phi)$, where $\omega$ is the radian frequency and $\phi$ is direction. The near bottom orbital velocity amplitude $U_{b m}$, the equivalent periodic wave radian frequency $\omega_{r}$ and the dominant direction, $\phi_{w}$ can be calculated by following the procedure in Madsen [39].

The direction of the current $\phi_{c}$ can be obtained as $\tan \phi_{c}=\frac{\tau_{b y}}{\tau_{b x}}$ from the circulation model. The angle between waves and current $\phi_{w c}$ is defined as $\phi_{c}-\phi_{w}$. The maximum wave bottom shear stress can be obtained from

$\tau_{w m}=\frac{1}{2} \rho_{w} f_{w c} U_{b m}^{2}$

where the combined wave-current friction factor, $f_{w c}$, is a function of the relative strength of currents and waves, specified by

$$
f_{w c}=C_{\mu} \exp \left\{5.61\left(\frac{C_{\mu} U_{b m}}{k_{n} \omega_{r}}\right)^{-0.109}-7.30\right\} \text {. }
$$

where,

$\mu=\frac{\tau_{c}}{\tau_{w m}}, \quad C_{\mu}=\left\{1+2 \mu\left|\cos \phi_{w c}\right|+\mu^{2}\right\}^{\frac{1}{2}}$.

Equations (13) and (14) are solved iteratively, by first assuming $\mu=0$ and $C_{\mu}=1$ to obtain an initial estimate of $\boldsymbol{\tau}_{w m}$ from (12) and (13). With this value of $\tau_{w m}, \mu$ and $C_{\mu}$ are updated using equation (14) and the procedure is repeated till convergence of $\mu$ is obtained with two significant digits.

Then, the wave boundary layer thickness is given as

$\delta_{w c}=A \kappa \frac{\sqrt{\frac{C_{\mu} \tau_{w m}}{\rho_{w}}}}{\omega_{r}}$,

using the final values for $C_{\mu}$ and $\tau_{w m}$ and the scaling factor [40],

$$
A=\exp \left\{2.96\left(\frac{C_{\mu} U_{b m}}{k_{N} \omega_{r}}\right)^{-0.071}-1.45\right\} \text {. }
$$

Finally, the apparent roughness is obtained by solving the equation

$Z_{o b}=\delta_{w c}\left[\frac{30 \delta_{w c}}{k_{N}}\right]^{-\sqrt{\frac{\tau_{c}}{C_{\mu} \tau_{w m}}}}$.
With the above results, the corresponding value of bottom friction coefficient $C_{z_{r}}$ can be updated by equation (7).

\subsubsection{Coupling Procedure}

As mentioned above, in this study, there are two types of wave effects incorporated into the hydrodynamic model POM: through surface shear stress and bottom stress. The coupling of the two models takes place in the following sequence. Firstly, wave model calculates the directional wave spectrum and significant wave height with wind inputs. The outputs are then used to estimate the total surface stress by Equations (3) - (5). These coupling values are then input into hydrodynamic model to model the circulations. In this study, the coupling process is one-way, which takes place every $1800 \mathrm{~s}$.

\section{APPLICATION DOMAIN}

The modified ocean circulation model is applied to the South East Asian Seas. It covers the domain of $99^{\circ} \mathrm{E}-121^{\circ} \mathrm{E}$ and $9^{\circ} \mathrm{S}-24^{\circ} \mathrm{N}$. A horizontal grid resolution of $1 / 6$ degree and 20 Sigma-level are employed. As initial 720-day spin-up period is used, starting from an initial of stationary state with climatological March temperature and salinity field [41], which is driven by the climatological mean wind. From March 01, 2001 (day 721), the analyzed wind fields from ECMWF (European Commission for Medium Weather Forecasting) are applied to drive the model. The results shown in the following sections are in the domain of $115^{\circ} \mathrm{E}$ $121^{\circ} \mathrm{E}$ and $13^{\circ} \mathrm{N}-24^{\circ} \mathrm{N}$. The study area covers the shallow coastal waters from the southern China coastline to the northern deep basin of South China Sea, as shown in Fig. (1).



Fig. (1). The bathymetry in the domain. 


\subsection{Wind Waves}

In this study, the wave-induced surface and bottom stresses were considered in addition to the effect of currents. The wave model was set up over a larger domain of $99^{\circ} \mathrm{E}-$ $170^{\circ}$ and $9^{\circ} \mathrm{S}-52^{\circ} \mathrm{N}$ with a bathymetric resolution of $1 / 6^{\circ}$, spectral resolution of 25 logarithmically spaced frequency components with $f_{l}=0.052 \mathrm{~Hz}$. The angular resolution is $30^{\circ}$. ECMWF winds at $0.5^{\circ}$ resolution are used to drive the model. The model was calibrated and verified by using the available buoy measurements located at $\left(121^{\circ} 55^{\prime} 25^{\prime}, \mathrm{E}\right.$, $25^{\circ} 5^{\prime} 46^{\prime}$ 'N) over the period of $1^{\text {st }}$ June $-31^{\text {st }}$ October 2001.
The buoy wave data $\left(H_{s}\right)$ are shown in good agreement with the model predictions for the five months period in Fig. (2).

Our study period is in April and May 2001, which is the inter monsoon period, when the wind direction is changing from the Northeast monsoon to the Southwest monsoon. During this transition time, a storm occurred during May 1113, 2001, as shown in Fig. (3). A strong northeast wind of about $13 \mathrm{~m} / \mathrm{s}$ was recorded, extending from the Taiwan Strait to the Luzon Strait, and results the significant wave height and the peak wave period from WAM shown in Fig. (4). On May 12, 2001, the significant wave heights reached $3 \mathrm{~m}$ in

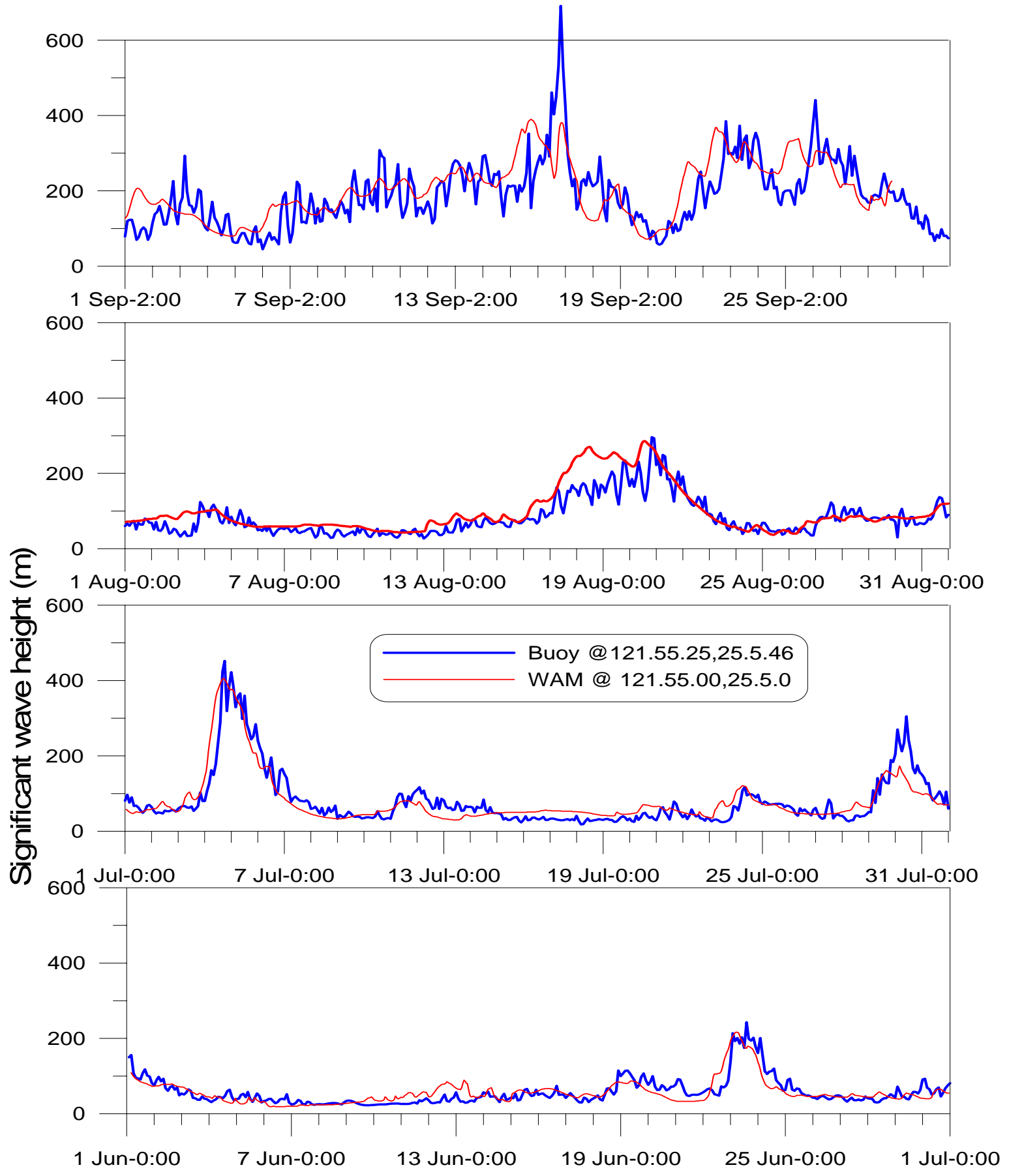

Fig. (2). The comparison between the prediction and the buoy observation of significant wave heights over five month's period from June October, 2001. 


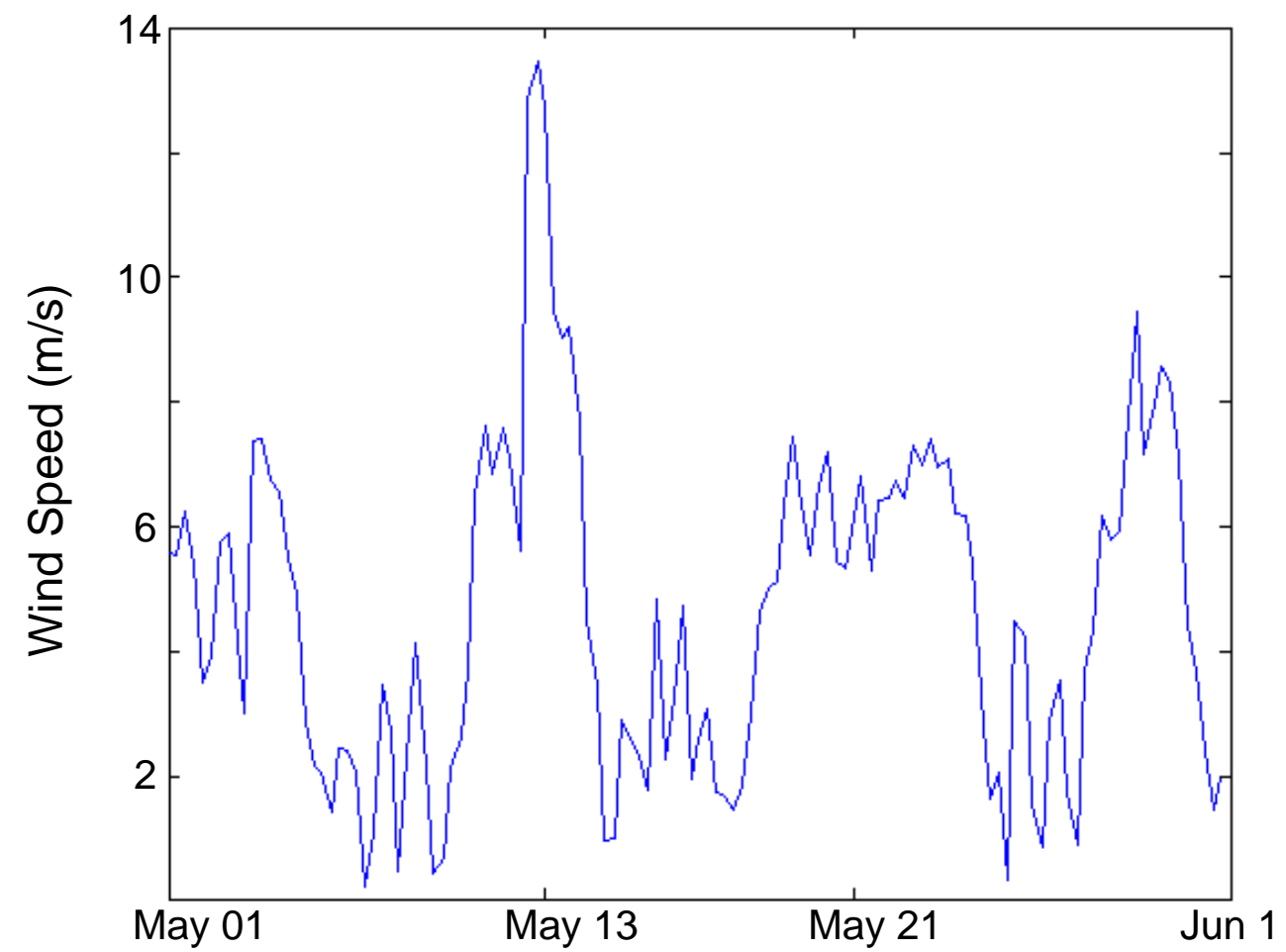

Fig. (3). The wind speed at (18N, 118E) in May 2001.
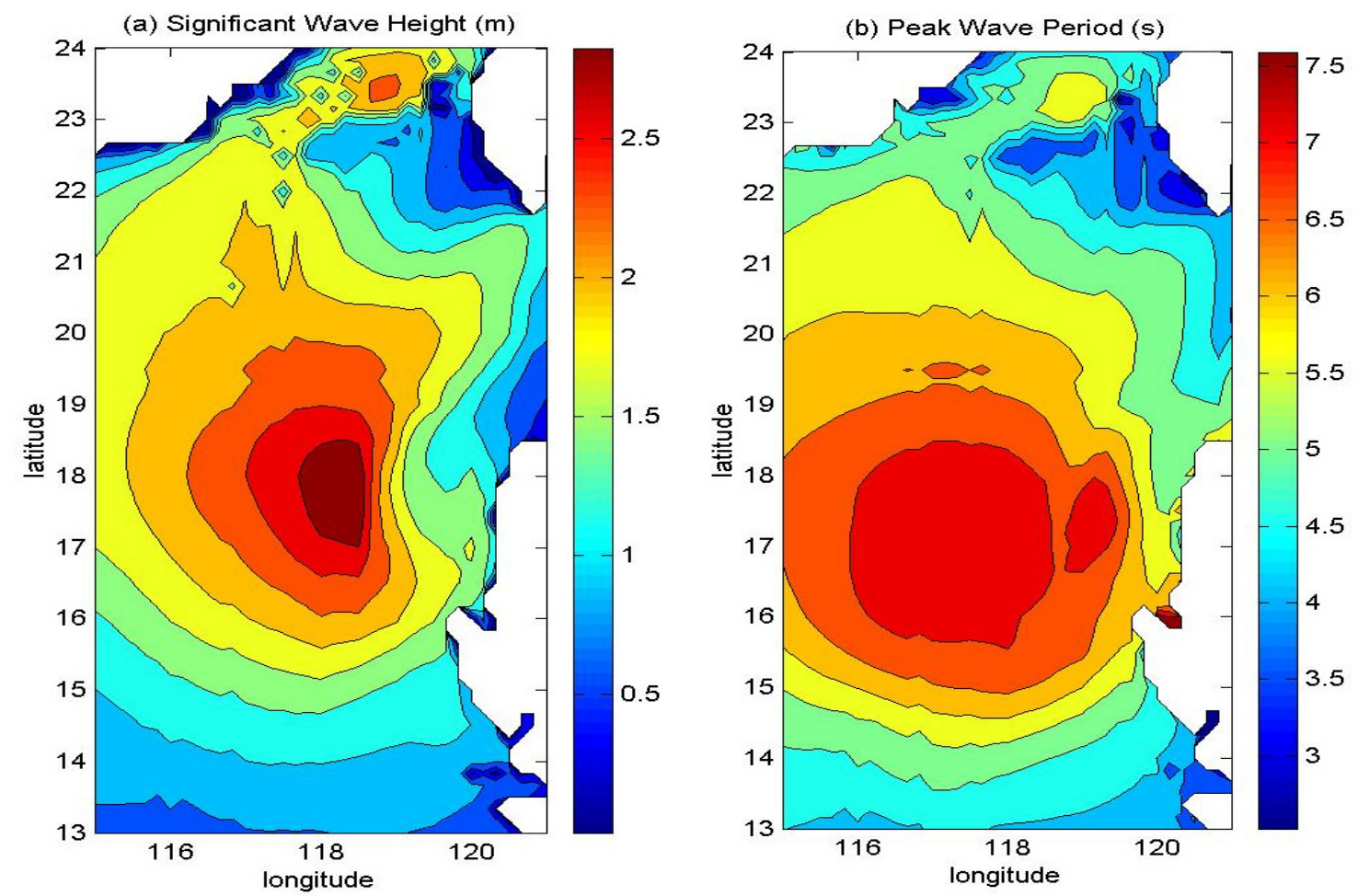

Fig. (4). The significant wave height and peak wave period on May 12, 2001.

the deep central domain. The peak wave period reached $7 \mathrm{~s}$ in the deep basin where the wind-waves were fully developed. However the peak period is only $2.5-3.5 s$ in the shallow coastal water region. The influence of the windgenerated waves on the current is to be investigated.

\subsection{Influence Through the Surface Stress}

The drag coefficients estimated by equations (2) and (4) are used to calculated surface shear stress. Equation (2) does not taken into account wave effects. The drag coefficient indirectly paramterized through surface roughness is pre- 
dicted by equations (3)-(5), where wave effects have be taken into account. Fig. (5a) shows surface shear stress depending only on the wind speed reaches up to $0.3 \mathrm{~N} / \mathrm{m}^{2}$ in the period of May 10-13, 2001. However, the surface stress including the wave contribution is illustrated in Fig. (5b); the magnitude of the stress is determined to be up to $0.6 \mathrm{~N} / \mathrm{m}^{2}$. The difference of the surface shear stress is due to wave effects as shown in Fig. (5c). These results show that the im- pacts of waves reach a maximum on May 12, 2001 with the rapid intensification of the cyclone. Figs. (5a-c) clearly illustrate that the presence of waves greatly enhance the magnitude of the surface stress. In previous studies, the drag coefficient is shown to increase with wind speed as long as storm intensity does not exceed $30 \mathrm{~m} / \mathrm{s}$ [17, 38, 42]. In the present study, the maximum wind speed is less than $15 \mathrm{~m} / \mathrm{s}$.



May 11, 2001

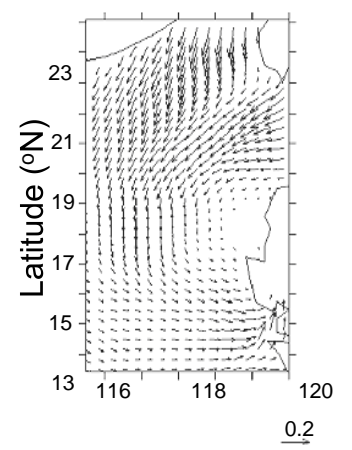

May 12, 2001

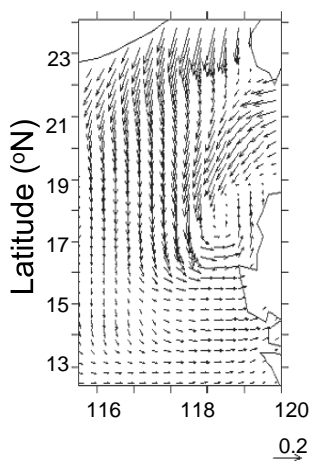

May 13, 2001

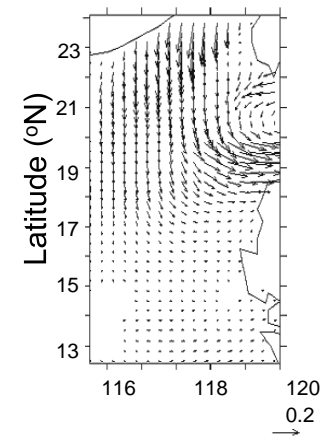

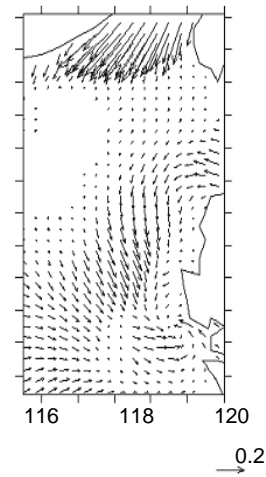
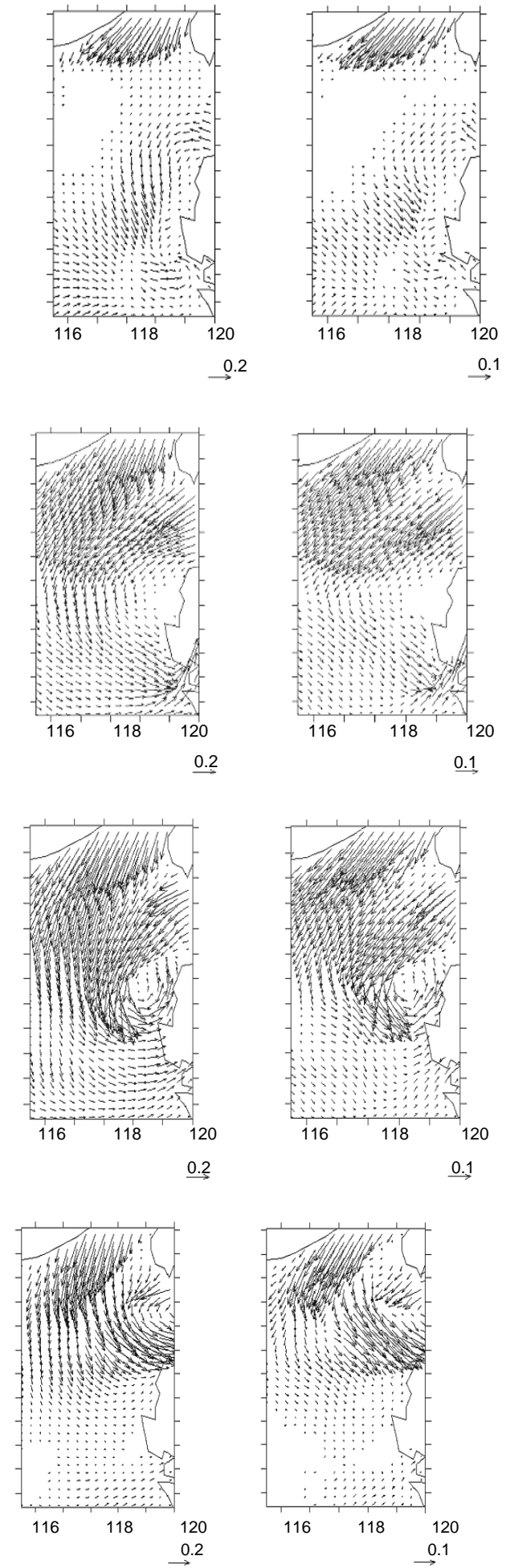

Fig. (5). The surface stress $\left(\mathrm{N} / \mathrm{m}^{2}\right)$ distribution. (a) wave-independent (b) wave-dependent (c) difference between (b) and (a). 
Fig. (6) further shows the comparison between the surface stresses calculated by Equations (2) and (4). Fig. (6a) illustrates that with the greater wind speed the influence to the surface stress is greater. For low wind speed, the wave effect is not significant, but at wind speeds above $10 \mathrm{~m} / \mathrm{s}$, the magnitude of the surface stress can be doubled. Fig. (6b) indicates that for developing waves with smaller peak periods the surface stress is influenced more significantly than for well developed waves, in agreement with Drennan et al. [43]'s five recent field campaigns. It can be seen that Equations (3)-(5) includes the contribution of the surface wave to circulations. However, in the present study, the breaking wave induced current and the wave set-up haven't been investigated, which need to be further studied.
The wave-enhanced surface stress results in a greater increase in the surface velocity where the surface stress is enhanced, but the effect on the bottom velocity is only in shallow regions as shown in Fig. (7). The maximum difference for surface currents can reach $0.4 \mathrm{~m} / \mathrm{s}$ in the central part of the domain where the storm has its maximum intensity. The surface elevation also increases in the shallow region and the variation can be up to $0.12 \mathrm{~m}$, which reaches $50 \%$ of the surface elevation near the coast.

\subsection{Influence Through the Bottom Stress}

Wave stress, the bottom orbital velocity $U_{b m}$, direction $\phi_{w}$ and frequency $\omega_{r}$ can be evaluated from WAM outputs and used in the bottom layer module to estimate the bottom

(a)

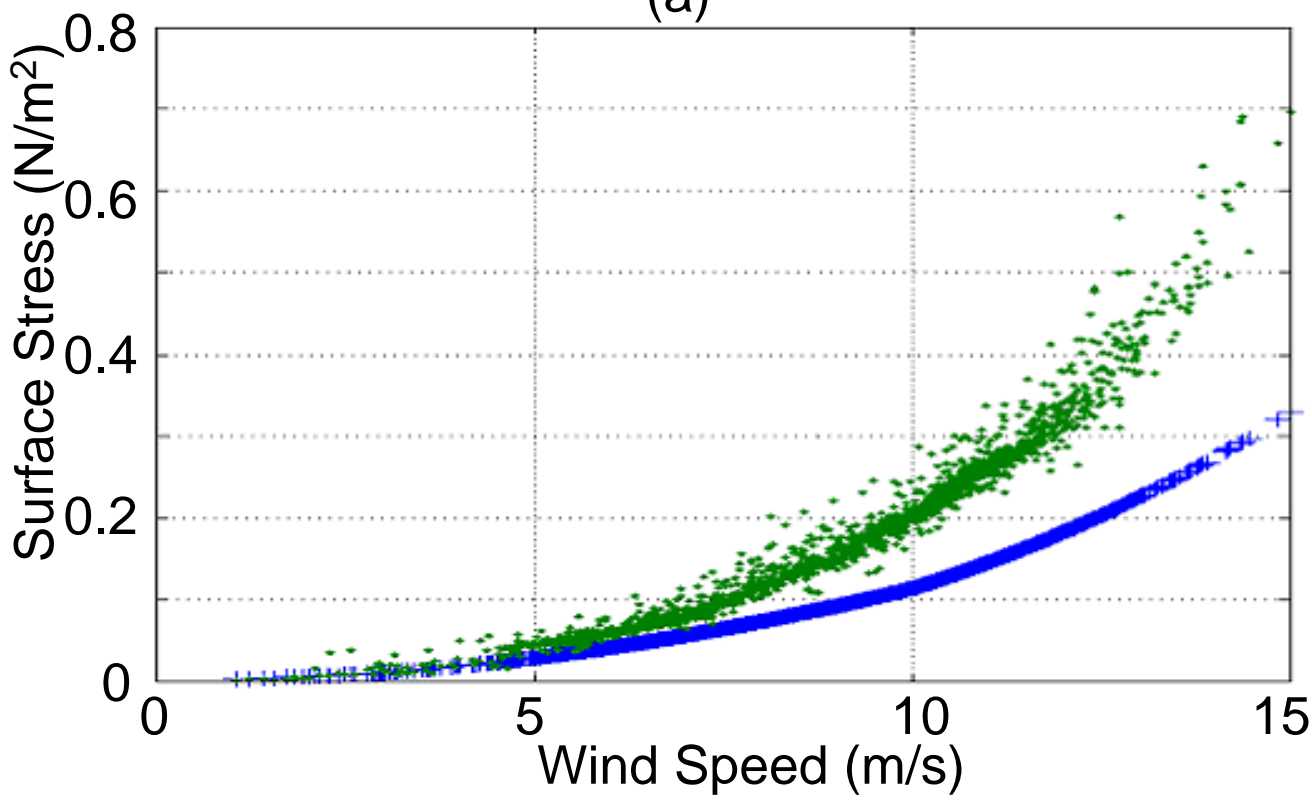

(b)

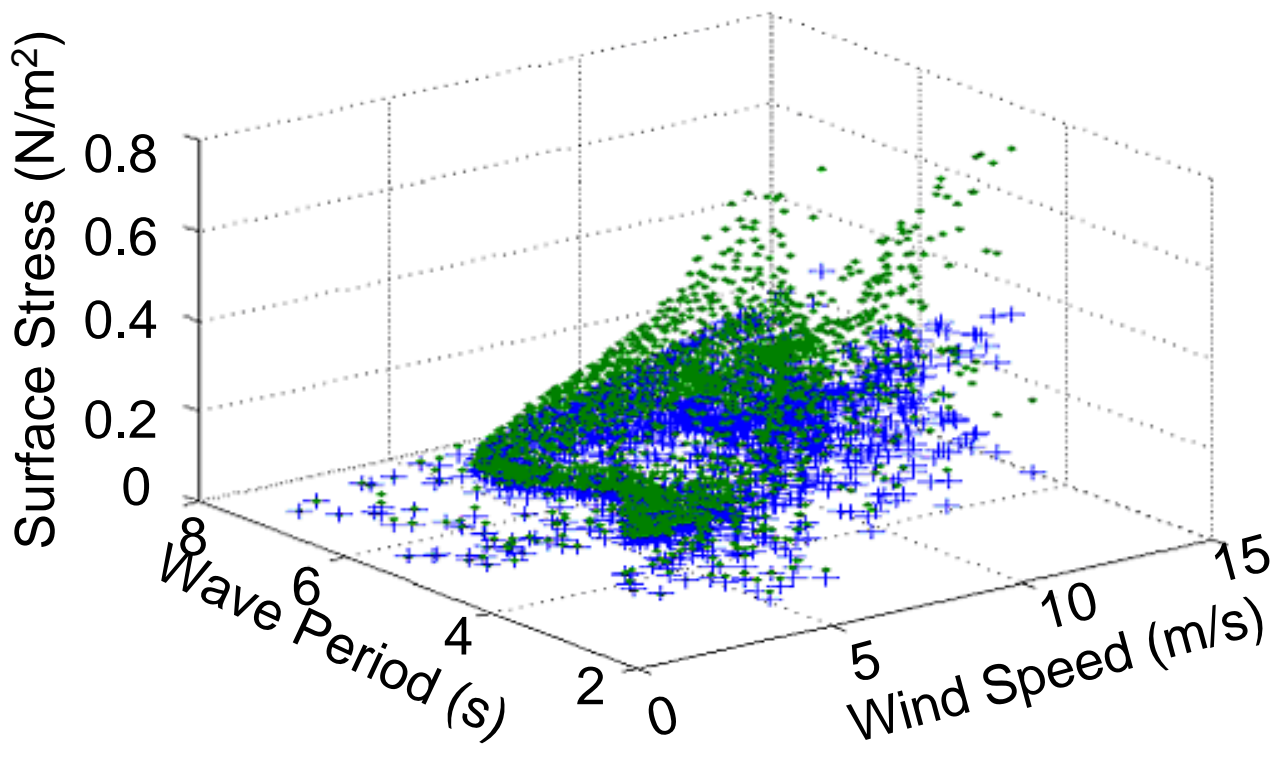

Fig. (6a). The relationship between the wind speed and the surface stress. (b) The relationship of the wind speed, the wave period and the surface stress. ( + without wave effects; ${ }^{*}$ with wave effects). 
roughness in POM. The procedure is the same as that described in Section 2.3. Fig. (8) shows the distribution of the bottom orbital velocity and the near bottom radian frequency on May 12 - 13, 2001. In the shallow waters near the northern open boundary, the values of $U_{b m}$ are large with a peak value of $0.5 \mathrm{~m} / \mathrm{s}$, and the bottom wave period diminishes to 3 $s$. Large values for $U_{b m}$ enhance the turbulence and increase the bottom roughness which can be as high as $0.06 \mathrm{~m}$. The effect of wave-current interaction on the bed friction coefficient reduces the currents near the coast because of the altering bottom stress. Several authors have previously addressed this effect $[30,10,31]$. Intensive turbulence retards the bottom flow. Far from the continental shelf areas, the wave effect on the current is insignificant. Fig. (9) confirms that the wave influence through the bottom stress increases in shallow water up to $40 \mathrm{~m}$ depth, which reduces the near bottom current up to $40 \%$, but has little effect on the surface current, although the surface elevation is reduced by up to $0.11 \mathrm{~m}$ near the northern boundary of the domain. As discussed in Zhang et al. [32], the influence of waves to the near bottom current is associated to water depths, wave periods, wave numbers and wave heights. In General, with water depth more than $50 \mathrm{~m}$ the wave effect is not significant.

The vertical extent of wave-associated turbulence is limited by the wave boundary layer. The wave contribution to the turbulent mixing must decrease with the distance away from the bottom. It should be noted that near-bottom turbulent eddy viscosity, $K_{M}=\omega k U_{z}$, increases with increasing shear stress. The influence on sediment transport and the mixing of other substances is significant near the sea bottom.

\subsection{The Total Wind Wave Effect and Calibration using ASIAEX Data}

We have shown that surface wave affects the current through both the surface stress and the bottom stress. Fig. (10) presents the effects of waves through both the surface
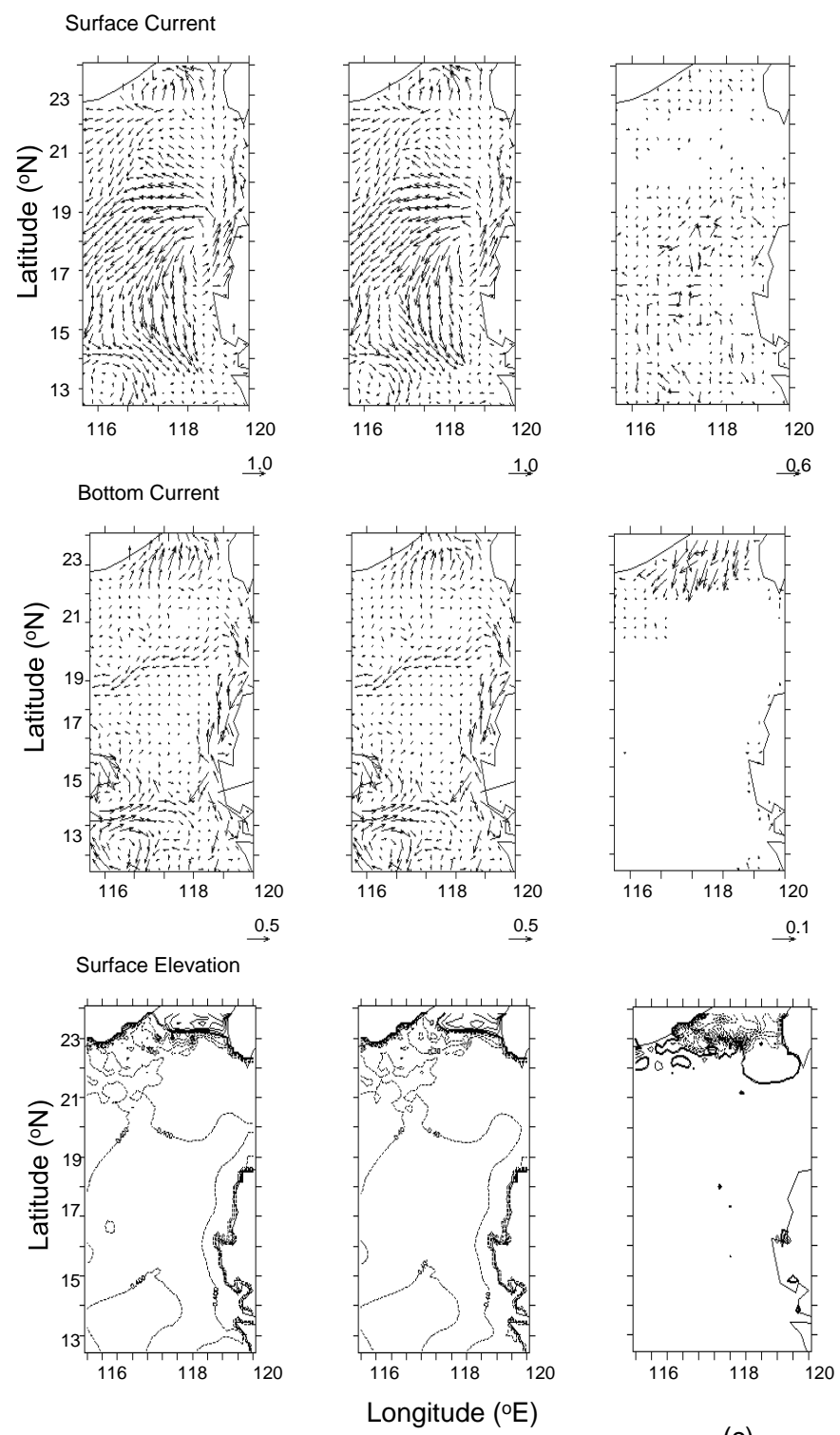

(a)

(b)

(c)

Fig. (7). The influence of wave through the surface to the surface current $(\mathrm{m} / \mathrm{s})$, bottom current $(\mathrm{m} / \mathrm{s})$ and surface elevation $(\mathrm{m})$. (a) waveindependent; (b) wave-dependent; (c) difference between (b) and (a). 

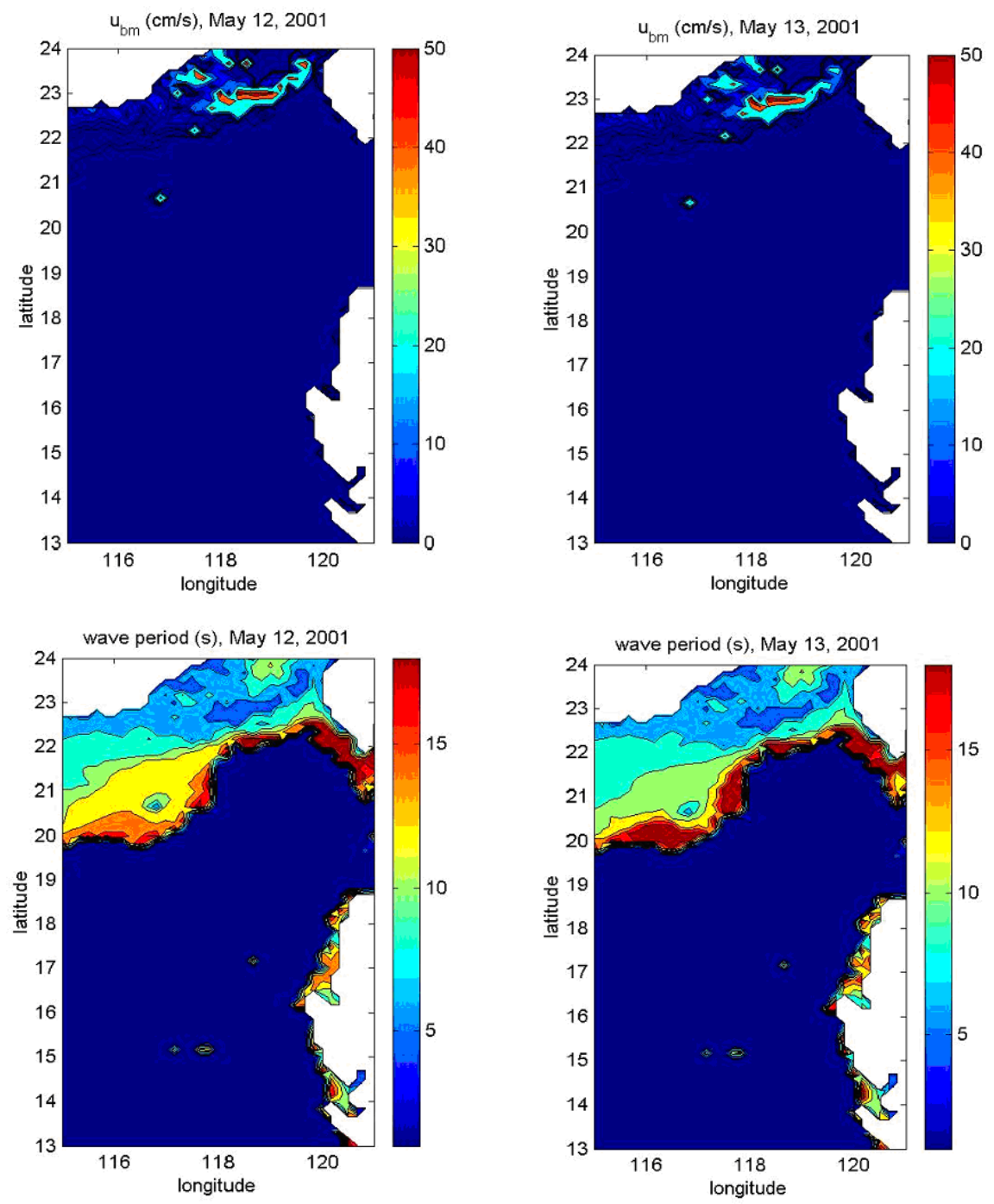

Fig. (8). The distribution of near bottom orbital velocity and wave period on May 12 and 13, 2001.

and bottom showing that the general flow pattern remains similar, regardless of the wave effect. Taking waves into account, an increased energy is input from the surface and more energy is dissipated from the bottom. These two effects are opposite. It can be seen from Fig. (8) that the surface and bottom current differences combine the results in Figs. ( 7 and 9). The surface current increases mainly due to the enhanced total surface stress and the bottom current decreases due to the net influence of the surface and the bottom stress. The influence of greater bottom turbulent intensity in the shallow water however, is dominant. The influence on elevation is also the net influence from both the surface and the bottom. As the tidal elevation variation has been added at the open boundaries, the diurnal and semi-diurnal cycles can be predicted as observed in Fig. (11).

The ASIAEX field experiment was conducted from 25 April to 19 May 2001. Measured current data at $8 \mathrm{~m}$ depth at location $(22.18 \mathrm{~N}, 117.06 \mathrm{E})$ is compared with simulated data for the period from April 21- May 19, 2001 (Fig. 11). The correlations between the measured data and the simulated data are 0.53 and 0.55 , respectively, without and with waves. If we only compare the period May 10-13, 2001, the correla- tion coefficients are 0.50 and 0.56 , which indicates that under strong wind the influence of waves is more significant.

Waves influence surface stress [43] play an important role in ocean mixing processes [44], which affects not only SST but the three-dimension temperature and salinity as well [11]. Analysis of CTD data in ASIAEX result in temporal and spatial variation patterns for the vertical profiles of temperature and salinity. Therefore, we compare model outputs at a given point with the field measurement data in Fig. 12. Although model temperature profiles agree well with observed data, the predicted salinity is higher than measured salinity at all locations. This may due to the fact that the model surface salinity is from climatologic data which might not accurately reflect the synoptic - scale processes such as rainfall. The temperature profile near the bottom also exhibits a difference between the predicted and measured data, which may be due to the seasonal averaged lateral boundary conditions, which were prescribed. Both wave enhanced turbulent mixing and depth induced wave breaking influence the hydrodynamic and thermodynamic process in the water column, but neither is investigated in the study. Further research of the influence of the wave on ocean circulations is to be carried out. 

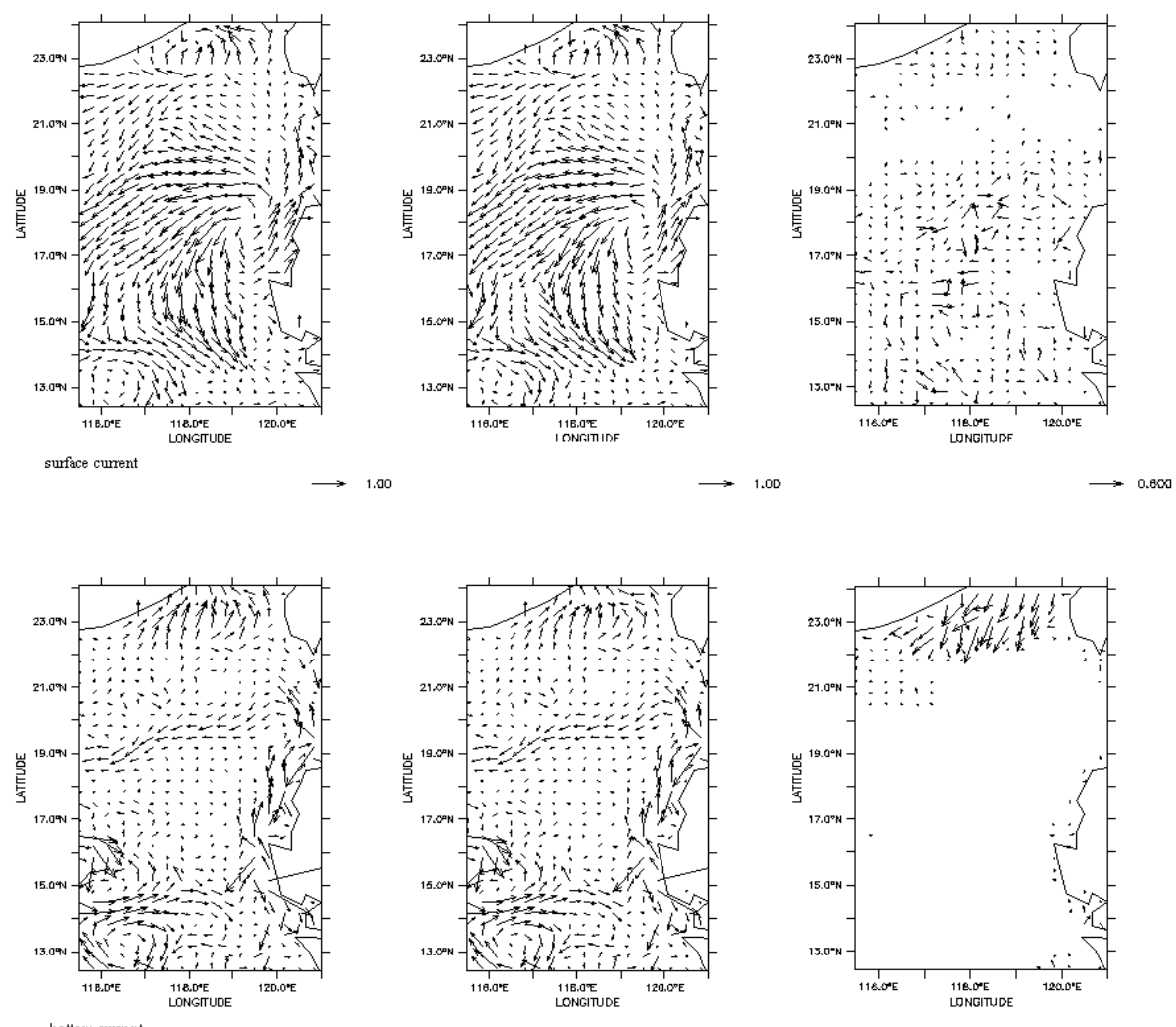

bottom current $\rightarrow 0.500$ $\longrightarrow 0.500$ $\longrightarrow 0.100$



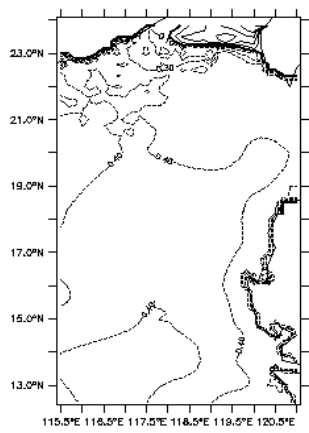

(b)



(c)

Fig. (9). The influence of wave through the bottom to the surface current $(\mathrm{m} / \mathrm{s})$, bottom current $(\mathrm{m} / \mathrm{s})$ and surface elevation $(\mathrm{m})$. (a) waveindependent; (b) wave-dependent; (c) difference between (b) and (a).

\section{CONCLUSIONS}

The influence of the wind waves on the ocean circulation was investigated. The improved formulation of the surface stress depends on the wind speed and the roughness of the water surface, which is prescribed to update the surface drag coefficient in the circulation model. The modified GrantMadsen analytical model [33] for the bottom roughness is applied to produce values of the apparent bottom roughness experienced by a current. The knowledge of wind-wave and current bottom shear stress and bottom sediment characteristics was incorporated into the circulation model. Its utility has been examined by presenting results generated in the South China Sea.
When the wave-enhanced surface stress is accounted for in the model, the impacts of strong winds is significant for surface current, but only affects the bottom current in shallow waters. Wind waves have significant bottom orbital velocity in the shallow water, which enhances bottom turbulence and retards the flow near the seabed. Our results suggest that waves have significant impacts in shallow regions, and high wave and low peak period conditions. We consider the influence of waves on the circulation through the surface and through the bottom. Comparison with the ASIAEX field measurements show that taking waves into account can improve the correlation between modeled and measured currents from 0.50 to 0.56 . 

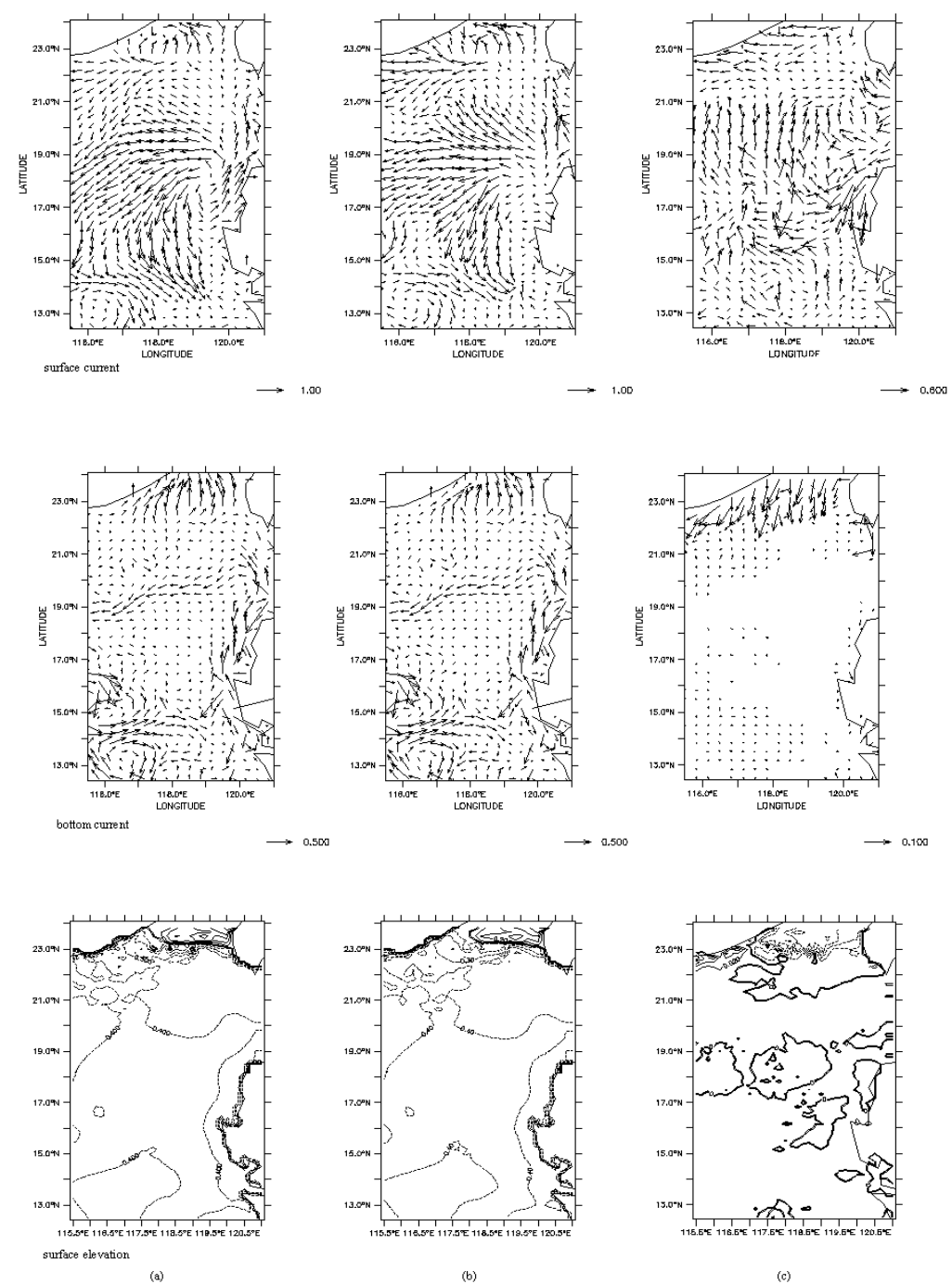

Fig. (10). The net influence of wave through the surface and the bottom to the surface current $(\mathrm{m} / \mathrm{s})$, bottom current $(\mathrm{m} / \mathrm{s})$ and surface elevation $(m)$. (a) wave-independent; (b) wave-dependent; (c) difference between (b) and (a).
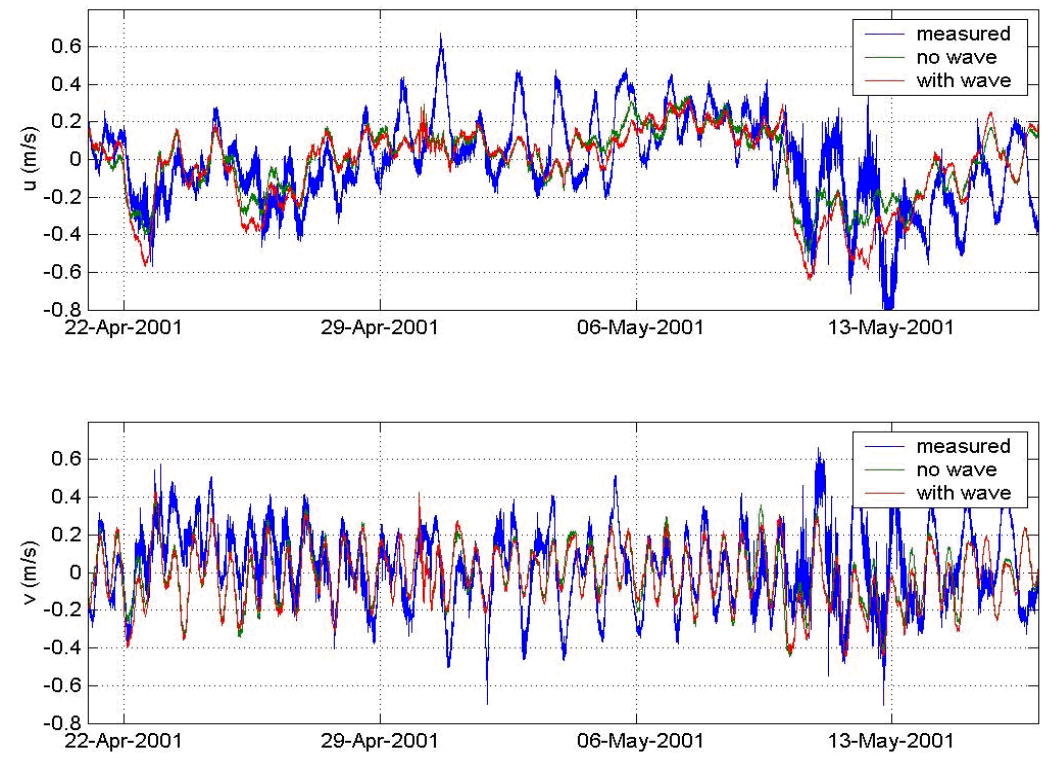

Fig. (11). Current comparison between the measured data and simulated data. 



Fig. (12). Temperature and salinity comparison between the measured data and simulated data.

In the present study, we examined only the influence of wind waves on the hydrodynamics. Further study on the sediment transport and the trajectory of water particles is ongoing, to obtain a better prediction capacity of the ocean environment. The effect of wind waves on the thermal dynamics will also be considered in a future study.

\section{ACKNOWLEDGEMENTS}

The authors wish to thank Prof. O. S. Madsen for his valuable discussions and suggestions on the theory of wavecurrent interaction near the seabed. 


\section{REFERENCE}

[1] E. J. Metzger and H. E. Hurlburt, "Coupled dynamics of the South China Sea, the Sulu Sea, and the Pacific Ocean", J. Geophys. Res., vol. 101, no. C5, pp. 12331-12352, 1996.

[2] S. Cai, J. Su, Z. Gan and Q. Liu, "The numerical study of the South China Sea upper circulation characteristics and its dynamic mechanism, in winter", Cont. Shelf Res., vol. 22, pp. 2247-2264, 2002.

[3] P. C. Chu and C. P. Chang, "South China Sea warm pool boreal spring", Adv. Atmos. Sci., vol. 14, pp. 195-206, 1997.

[4] P. C. Chu and C. P. Chang, "Dynamical mechanisms for the South China Sea seasonal circulation and thermohaline variabilities", $J$. Phys. Oceanogr., vol. 29, no. 11, pp. 2971-2989, 1999.

[5] S. Hasselmann and K. Hasselmann, "Computations and parameterizations of the nonlinear energy transfer in a gravity wave spectrum. Part I: A new method for efficient computations of the exact nonlinear transfer integral", J. Phys. Oceanogr., vol. 15, no. 11, pp. 1369-1377, 1985.

[6] S. Hellerman and M. Rosenstein, "Normal monthly wind stress over the world ocean with error estimates", J. Phys. Oceanogr., vol. 13, pp. 1093-1104, 1983.

[7] R. L. Snyder, F. W. Dobson, J. A. Elliot and R. B. Long, "Array measurements of atmospheric pressure fluctuations above surface gravity waves", J. Fluid Mech., vol. 102, pp. 1-59, 1981.

[8] K. Wyrtki, "Scientific results of marine investigations of the South China Sea and Gulf of Thailand 1959-1961", NAGA report 2.

[9] A. M. Davies and J. Xing, "Modelling of turbulent mixing at the shelf edge", Cont. Shelf Res., vol. 20, pp. 1789-1823, 2000.

[10] L. Xie, K. Wu, L. Pietrafesa and C. Zhang, "A numerical study of wave-current interaction through surface and bottom stress Part I: Wind-driven circulation in the South Atlantic Bight under uniform winds", J. Geophys. Res., vol. 106, pp. 16841-16856, 2001.

[11] I. Moon, "Impact of a coupled ocean wave-tide-circulation system on coastal modelling", Ocean Model., vol. 8, pp. 203-236, 2005.

[12] W. G. Large and S. Pond, "Open ocean momentum fluxes in moderate to strong winds", J. Phys. Oceanogr., vol. 11, pp. 324-336, 1981.

[13] H. Charnock, "Wind stress on a water surface", Q.J.R. Meteorol. Soc., vol. 81, pp. 639-640, 1955.

[14] P. A. E. M. Janssen, "Wave-induced stress and the drag of airflow over sea waves", J. Phys. Oceanogr., vol. 21, pp. 745-754, 1989.

[15] P. A. E. M. Janssen, "Quasi-linear theory of wind wave generation applied to wave forecasting", J. Phys. Oceanogr., vol. 19, pp. 1631-1642, 1991.

[16] M. A. Donelan, F. W. Dobson and S. D. Smith, "On the dependence of se surface roughness on wave development", J. Phys. Oceanogr., vol. 23, pp. 2143-2149, 1993.

[17] M. A. Donelan, B. K. Haus, N. Reul, W. J. Plant, M. Stiassnie, H. C. Graber, O. B. Brown and E. S. Saltzman, "On the limiting aerodynamic roughness of the ocean in very strong winds", Geophys. Res. Lett., vol. 31, L18306, 2004.

[18] S. R. Massel and R.M. Brinkman, "Wave-induced setup and flow over shoals and coral reefs", Oceanologia, vol. 43, pp. 373-388, 2001.

[19] G. L. Mellor, Users guide for a three-dimensional, primitive equation, numerical ocean model (June 2003 version), 53 pp., Prog. in Atmos. and Ocean. Sci, Princeton University, 2003.

[20] F. Qiao, Y. Yuan, Y. Yang, Q. Zheng, C. Xian and J. Ma, "Waveinduced mixing in the upper ocean: Distribution and application to a global ocean circulation model", Geophys. Res. Lett., vol. 31, L11303, 2004.

[21] P. D. Craig and M. L. Banner, "Modeling wave-enhanced turbulence in the ocean surface layer", J. Phys. Oceanogr., vol. 24, pp. 2546-2559, 1994.

[22] H. Zhang and E. S. Chan, "Modeling of the turbulence in the water column under breaking wind waves", J. Oceanogr., vol. 59, no. 3, pp. 331-341, 2003.
[23] J. B. Christoffersen and I. G. Jonsson, "Bed friction and dissipation in a combined current and wave motion", Ocean Eng., vol. 12, no. 5, pp. 387-423, 1985.

[24] T. F. Gross, A. E. Isley and C. R. Sherwood, "Estimation of stress and bed roughness during storms on the North California Shelf", Cont. Shelf Res., vol. 12, no. 2/3, pp. 389-413, 1992.

[25] P. P. Mathisen and O.S. Madsen, "Waves and currents over a fixed rippled bed: I. Bottom roughness experienced by waves and II. Bottom and apparent roughness experienced by currents", J. Geophys. Res., vol. 101(C7), no. 16, pp. 533-16, 550, 1996.

[26] N. Booij, R. Ris and L. Holthuijsen, "A third-generation wave model for coastal regions, 1 . model description and validation", $J$. Geophys. Res., vol. 104, no. 4, pp. 7649-7666, 1999.

[27] W.D. Grant and O.S. Madsen, "Combined wave and current interaction with a rough bottom", J. Geophys. Res., vol. 84, pp. 1797$1808,1979$.

[28] W. D. Grant and O. S. Madsen, "The continental shelf bottom boundary layer", Ann. Rev. Fluid Mech., vol.18, pp. 265-305, 1976.

[29] W. D. Grant, A. J. III Williams and S. M. Glenn, "Bottom stress estimates and their prediction on the northern California continental shelf during CODE-1: the importance of wave-current interaction", J. Phys. Oceanogr., vol. 14, pp. 506-527, 1984.

[30] R. P. Signell and J. List, "Effect of wave-enhanced bottom friction on storm-driven circulation in Massachusetts Bay", J. Waterway, Port, Coast. Ocean Eng., vol. 123, no. 5, pp. 233-239, 1997.

[31] M. Y. Zhang and Y. S. Li, "The dynamic coupling of a thirdgeneration wave model and a 3D hydrodynamic model through boundary layers", Cont. Shelf Res., vol. 17, no, 10, pp. 1141-1170, 1997.

[32] H. Zhang, O. S. Madsen, S. A. Sannasiraj and E. S. Chan, "Hydrodynamic model with wave-current interaction in coastal regions", Estuar. Coast. shelf Sci., vol. 61, pp. 317-324, 2004.

[33] O. S. Madsen, "Sediment Transport outside the Surf Zone", In: Walton, T. (Ed), Coastal Engineering Manual, Part III Coastal Processes, Engineer Manual 1110-2-1100, U.S. Army Corps of Engineers, Washington D.C., 2002.

[34] G. J. Komen, L. Cavaleri, M. Donelan, K. Hasselmann, S. Hasselmann, P. A. E. M. Janssen, Dynamics and modeling of ocean waves, Cambridge University Press, New York, 1994.

[35] K. E. Trenberth, "Recent observed inter-decadal climate changes in the Northern Hemisphere", Bull. Amer. Meteor. Soc., vol. 71, pp. 988-993, 1990.

[36] A. Andrey, C. W. Fairall, J. E. Hare and J. B. Edson, "Wind Stress Vector Over Sea Waves", The 11th Conference on Interaction of the Sea and Atmosphere, San Diego, CA, USA, May 14-17, 2001.

[37] H. K. Johnson and H. J. Vested, "Effects of Water Waves on Wind Shear Stress for Current Modeling", J. Atmos. Ocean. Technol., vol. 9, no. 6, pp. 850-861, 1992.

[38] J. A. Bye and A. D. Jekins, "Drag coefficient reduction at very high wind speeds", J. Geophys. Res., vol. 111, C03024, 2006.

[39] O. S. Madsen, "Spectral wave-current bottom boundary layer flows", Proc. 24th ICCE. ASCE, 1:384-398, 1995.

[40] P. P. Mathisen and O. S. Madsen, "Waves and currents over a fixed rippled bed: III. Bottom and apparent roughness for spectral waves and currents", J. Geophys. Res., vol. 104(C8), no. 18, pp. 447$18,461,1999$.

[41] WOA98, World Ocean Atlas 1998, CD-ROM Documentation version 1.0, Ocean Climate Laboratory, National Oceanographic Data Center, USA, April 1999.

[42] M. D. Powell, P. J. Vickery and T. A. Reinhold, "Reduced drag coefficient for high wind speeds in tropical cyclones", Nature, vol. 422, pp. 279-283, 2003.

[43] W. M. Drennan, G. C. Graber, D. Hauser and C. Quentin, "On the wave age dependence of wind stress over pure wind seas", J. Geophys. Res., vol. 108 (C3), pp. 8062, 2003.

[44] G. L. Mellor and A. Blumberg, "Wave breaking and ocean surface thermal response", J. Phys. Oceanogr., vol. 34, pp. 693-698, 2004. 